\title{
Nódulos com Diagnóstico de Padrão Folicular: Marcadores Biológic os São o Futuro?
}

\section{perspectiva}

\section{JANete M. CeruttI}

Disciplina de Genética, Departamento de Morfologia e Disciplina de Endocrinologia, Departa mento de Medicina, Universida de Federal de São Paulo, SP.

Recebido em 12/02/07 Aceito em 16/02/07

\section{RESUMO}

Com o uso da ultra-sonografia de alta resolução, a prevalência de nódulos tem aumentado e, conseqüentemente, o número de punção aspirativa por agulha fina (PAAF), que é o método de escolha para diagnóstico inicial. Um dos maiores dilemas clínicos para o citologista é o diagnóstico diferencial das lesões foliculares comumente agrupadas na classe padrão folicular. Neste artigo de revisão, discutiremos quais são as lesões que podem ser assim classificadas e os marcadores moleculares, identificados por nós ou por outros grupos, que são capazes de distinguir as lesões benignas das malignas. (Arq Bras Endocrinol Metab 2007;51/5:832-843)

Descritores: Padrão folicular; Marcadores moleculares; Adenoma folicular da tiróide; Carcinoma folicular da tiróide; PAAF; Diagnóstico

\section{ABSTRACT}

\section{Nodule Diagnosed as Follicular Patterned Lesion: Are Biomarkers the Promise?}

There are an increasing number of thyroid nodules found by ultrasound and sampled by fine needle aspiration (FNA). A clinical problem is the accurate distinction between benign and malignant forms of follicular lesion. In this review we discuss the thyroid lesions that are common sources of diagnostic error, and grouped together as follicular patterned lesion, and the molecular markers identified by us and others, and that are able to distinguish the benign from the malignant ones. (Arq Bras Endocrinol Metab 2007;51/5:832-843)

Keywords: Follicular patterned; Biomarkers; Follicular thyroid adenoma; Follicular thyroid carcinoma; FNA; Diagnosis

\section{NÓDULO COM DIAGNÓSTICO DE PADRÃO FOUCULAR, "A CATCHALTERM"}

S NÓDULOS DA TIRÓIDE SÃO ENCONTRADOS em prevalência de aproximadamente 4-7\% na população. Com o advento da ultra-sonografia de alta resolução, uma técnica simples, barata, de fácil acesso e sensível, capaz de identificar nódulos a partir de $2 \mathrm{~mm}$, a prevalência de nódulos pode chegar a $67 \%(1,2)$. Portanto, na maioria das vezes, os nódulos são impalpáveis e identificados nas ultra-sonografias cervicais realizada por razões nem sempre relacionadas à tiróide. Sendo os nódulos da tiróide um problema clínico comum, o que o médico deve fazer?

A conduta clínica depende da avaliação inicial. 0 método de escolha para avaliação inicial dos nódulos tiroidianos, na maioria dos serviços, é a punção aspirativa por agulha fina (PAAF) com subseqüente análise citológica. O principal objetivo da PAAF é diferenciar os nódulos com 
maior risco de malignidade, e que devem ser encaminhados para cirurgia, dos nódulos tiroidianos, que devem ser seguidos clinicamente.

$\mathrm{N}$ a citologia, os nódulos podem ser classificados como benignos (60-70\%), malignos (5-10\%), indeterminados (10-20\%) ou inadequados $(10-15 \%)(3,4)$. Q uanto aos nódulos diagnosticados como inadequados na citologia, estes podem ser submetidos a uma nova PAAF. No entanto, os nódulos classificados como indeterminados representam um dilema clínico devido à dificuldade de classificá-los como benignos ou malignos. Q uais são essas lesões cujo diagnóstico na PAAF representa um desafio para o citologista e diminui a acurácia do método?

Este dilema clínico ocorre, sobretudo, nos casos de adenoma folicular da tiróide (AFT) e de carcinoma folicular da tiróide (CFT) $(5,6)$. A dificuldade de diagnóstico diferencial é decorrente, além da semeIhança citológica das duas lesões, da impossibilidade de verificar na PAAF se há invasão de vasos e/ ou cápsula, que são os critérios que determinam malignidade. Para estes nódulos, tem sido recomendado o uso do termo lesão folicular ou, ainda, padrão folicular (PF).

Além do adenoma folicular e do carcinoma folicular, o termo citológico PF também pode incluir outras condições que podem levar a dificuldade no diagnóstico. Estas lesões são os nódulos hiperplásicos $(\mathrm{NH})$, adenomas de $\mathrm{H}$ ürthle $(\mathrm{AH})$, carcinomas de $\mathrm{H}$ ürthle $(\mathrm{CH})$ e a variante folicular do carcinoma papilífero da tiróide (VFCPT) (6-9). N os casos de AH e CH, que são considerados variantes dos tumores foliculares, os critérios de malignidade seguem àqueles determinados para o AFT e CFT e, portanto, necessitam de análise histológica para verificar invasão de vasos e/ ou cápsula. No caso da VFCPT, os critérios de diagnóstico citológico de carcinoma papilífero (CPT) podem estar ausentes e, nestes casos, apresentam características citológicas que se assemelham ao AFT ou CFT $(6,8)$.

Além disso, vários grupos observaram que um grande número dos casos de nódulos diagnosticados como PF na PAAF eram, na análise histológica final, casos de VFCPT, ou ainda de CPT (10-13). Estes achados demonstram que mesmo o CPT, cuja sensibilidade e especificidade na PAAF se aproxima de $100 \%$ também pode ser uma fonte de dificuldade para 0 diagnóstico na PAAF.

Embora de $10-30 \%$ de to das as PAAFs resultem no diagnóstico PF, e estes possam corresponder a qualquer uma das entidades acima citadas, na prática clínica somente $20 \%$ dos nódulos têm diagnóstico de carcinoma na análise histológica final $(3,14,15)$. Assim, a maior parte dos nódulos removidos cirurgica- mente são nódulos benignos (6). I sso se deve principalmente ao excesso de tratamento, pois, embora o diagnóstico falso-positivo na citologia de tireóide seja indesejável, a maior preocupação são os falso-negativos devido ao atraso no tratamento.

Para minimizar o número de cirurgias desnecessárias ou sérias conseqüências no atraso do tratamento, vários grupos têm procurado aumentar a sensibilidade e especificidade do teste pré-operatório.

Balochi e cols. sugerem que sejam observadas certas características nucleares sugestivas de CPT, os nódulos com diagnóstico de PF poderiam ser subdivididos em duas classes: neoplasias foliculares ou neoplasias foliculares suspeitas para CPT $(9,16)$. Levando em consideração tais características, o grupo observou uma taxa de malignidade de $35 \%$ nos casos de nódulos inicialmente diagnosticados como PF, e de $72 \%$ nos nódulos inicialmente classificados como PF suspeitos para CPT (17). Entre os nódulos diagnosticados como PF, a maioria era composta por AFT (33\%) e bócio (31\%), seguida por VFCPT (22\%). Entre os $72 \%$ inicialmente diagnosticados como suspeitos para CTP, o diagnóstico observado com maior freqüência foi de VFCPT (54\%), seguido por bócio nodular (20\%), CPT (12\%), AFT (8\%), CFT (4\%) e CCH (2\%).

$\mathrm{N}$ os casos de AFT, CFT, ACH e CCH, cujo critério de diferenciação é invasão de vasos e/ ou cápsula, a análise citológica isoladamente não resultará no aumento da acurácia do teste. Vários protocolos foram realizados com o intuito de determinar parâmetros clínicos que pudessem identificar os nódulos com alto risco de malignidade daqueles com menor risco (10). Entretanto, nenhum dos parâmetros foi satisfatório.

A compreensão do genoma humano e o avanço das técnicas moleculares têm revolucionado a prática clínica. Estes avanços tiveram profundas implicações no diagnóstico, no planejamento do tratamento individualizado e no desenvolvimento de novas drogas em várias áreas da medicina, incluindo a endocrinologia.

Com relação ao diagnóstico dos nódulos tiroidianos, vários grupos investigaram alterações genéticas específicas das lesões benignas ou malignas ou ainda investigaram o perfil de expressão gênica das lesões inicialmente classificadas como PF com o objetivo de identificar genes diferencialmente expressos que possam ser utilizados como marcadores de diagnóstico. Os marcadores identificados com estas análises têm sido testados quanto à eficiência em classificar os nódulos como benignos ou malignos utilizando várias metodologias como, por exemplo, RT-PCR, ensaio de atividade enzimática e imunoistoquímica. N este trabalho de revisão serão discutidos os principais marcadores mo- 
leculares identificados e que, em associação com a PAAF, oferecem perspectivas no diagnóstico diferencial dos nódulos inicialmente classificados como PF.

\section{PAX8-PPARY, UM MARCADOR MOLECULAR CAPAZ DE DIFRENCIAR AS LESÕES BENIGNAS DAS MALGNAS?}

Entre as alterações genéticas identificadas e inicialmente associadas à patogênese do $C F T$, destaca-se 0 rearranjo envolvendo os genes PAX 8 e PPAR $\gamma(18)$. Este evento somático de translocação justapõe a região 5 ' do gene PAX 8 (2q13) ao exon 1 do gene PPAR $\gamma$ (do inglês, peroxi some proliferator-activated receptor $\gamma$ ) (3p25). A té o momento, algumas variantes têm sido observadas em decorrência dos diferentes pontos de quebra no gene PAX 8, que podem ocorrer nos exons 7-9 $(19,20)$. As quebras observadas no gene PPA R $\gamma$ ocorrem no exon 1 do gene (figura 1). A proteína de fusão formada tem aproximadamente $87-99 \mathrm{kD} \mathrm{a}$.

$\mathrm{Na}$ descrição original, o gene quimérico formado em decorrência desta translocação estava presente em 5/ 8 (63\%) casos de CFT investigados. Por outro lado, o rearranjo não foi detectado em nenhum dos casos de adenoma folicular (0/20), bócio (0/ 10) e carcinoma papilífero da tiróide (0/10) (18). Os autores sugeriram que este marcador poderia diferenciar o CFT do AFT. Estes dados são extremamente interessantes porque é o primeiro evento genético associado especificamente com CFT e porque já havia sido observada em análise citogenética a perda de $3 p$ em CFTs, sugerindo que provavelmente nesta região haviam genes supressores de tumor (21).

Entretanto, vários grupos, incluindo o nosso, reportaram a ocorrência deste rearranjo em $8-55 \%$ dos casos de AFT $(20,22,23)$. Além disso, a freqüência do rearranjo nos casos de CFT é inferior à reportada por Kroll e cols., com uma prevalência acumulativa de $30 \%$ (24). O utras alterações envolvendo $3 p 25$ como, por exemplo, trissomia, tetrassomia e trissomia associada a monossomia parcial, foram identificadas em casos de CFT (25). R ecentemente, este rearranjo foi detectado em casos de VFCPT $(26,27)$. O s autores sugerem que alguns casos de VFCPT apresentam características moleculares semelhantes aos CFT.

A partir destes achados, muitas questões foram levantadas. Por exemplo, qual o real papel desta proteína na patogênese dos tumores foliculares? Este evento ocorre precocemente e, de fato, os AFT com este rearranjo são formas mais agressivas e devem ser tratados como CFT? Este marcador pode predizer a evolução clínica? Sendo PAX8 e PPAR $\gamma$ fatores de transcrição, quais são as vias de sinalização que estão comprometidas? Diferentes vias de sinalização foram ativadas em decorrência deste rearranjo? Serão as vias associadas ao PPAR $\gamma$ fundamentais, uma vez que aneuplodias envolvendo o 3p25 foram identificadas em casos de CFT? Eventos genéticos adicionais são necessários para a transformação maligna das células foliculares da tiróide? $\mathrm{N}$ ovas drogas que têm como alvo esta proteína de fusão serão mais eficientes no tratamento dos pacientes com CFT e rearranjo PAX 8-PPAR $\gamma$ ?

Com relação à expressão desta proteína e sua associação com a apresentação clínica e evolução, existem controvérsias. Em trabalhos posteriores, o grupo de Kroll reforça a sua posição de que este rearranjo está associado à patogênese dos CFT. 0 grupo sugere que o rearranjo ou a aneuplodia observada possam ser eventos subseqüentes a outras alterações e estão presentes em CFT mais agressivos. Discute, ainda, que a positividade nos casos de adenoma folicular, descrita pelos outros grupos, deve indicar a presença de carcinomas foliculares in situ e, portanto, AFT com um prognóstico menos favorável (25). Nikiforova e cols. confirmam a associação entre rearranjo PAX 8-PPA $\gamma$ e CFTs mais agressivos e sugerem que a exposição à radiação pode ser o mecanismo responsável pela geração deste evento genético (28). Sahin e cols. sugerem que a expressão da proteína de fusão, investigada através da expressão do PPAR $\gamma$ por imunoistoquímica, está asso ciada a um subtipo menos agressivo (29).

Com relação ao mecanismo molecular, Kroll e cols. acreditam que a proteína de fusão (figura 1) contribui para a patogênese do CFT porque inibe a função da proteína PPAR $\gamma$ normal produzida na célula através do efeito dominante-negativo (18). Martelli e

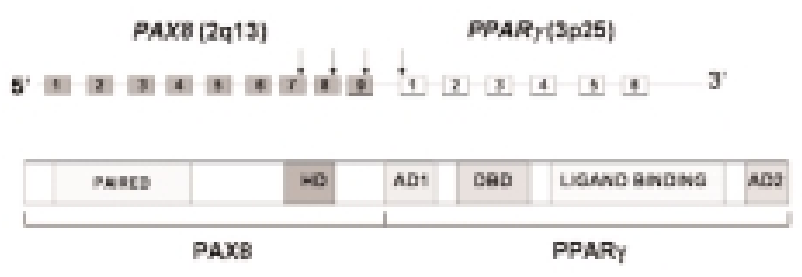

Figura 1. Rearranjo dos genes PAX8 e PPAR $\gamma$. O gene de fusão codifica uma proteína de aproximadamente $87-98 \mathrm{\kappa Da}$, dependendo do ponto de quebra no gene PAX8. Mais de uma isoforma podem ser detectadas no mesmo paciente. A proteína de fusão contém os domínios de ligação ao DNA que compreendem (PAIRED e HD) do gene PAX8 e os domínios de transativação (AD1 e AD2), associação ao ligando, dimerização com RXR e de ligação ao DNA (DBD) do gene PPAR $\gamma$. 
cols. demonstraram que a proteína PPAR $\gamma$, quando reexpressa em linhagens celulares de carcinoma de tiróide, inibe o crescimento celular, promove parada no ciclo celular e induz apoptose (30). Estudos posteriores demonstraram que a proteína de fusão foi capaz de estimular o crescimento das células, interferir na progressão do ciclo celular e inibir apoptose (31). M ais recentemente, em um modelo biológico onde a proteína de fusão foi constitutivamente expressa em diferentes linhagens celulares, foi demonstrado que as vias de sinalização controladas por PAX 8-PPA R $\gamma$ são complexas e dependem do tipo celular. Os autores acreditam que a inapropriada expressão de genes responsivos a PPAR $\gamma$ ou PA X 8, associada à inibição da expressão de outros genes, seja o mecanismo pelo qual essa proteína contribua para o crescimento celular e perda da diferenciação (32).

Embora esses trabalhos citados e outros que investigaram genes diferencialmente expressos nos tumores que apresentam este rearranjo $(33,34)$ tenham contribuído para a compreensão da patogênese dos tumores foliculares da tiróide, o papel do rearranjo PAX 8-PPAR $\gamma$ como marcador de malignidade não é consensual na literatura. Enquanto não for esclarecido se os casos de AFT com rearranjo PAX 8-PPAR $\gamma$ têm um prognóstico menos favorável e se tratam de carcinomas foliculares in stu, como interpretar os resultados em que este rearranjo está presente na PAAF? Além disso, sendo que este rearranjo tem uma freqüência acumulativa de $30 \%$ dos casos de CFT, qual a conduta para os casos negativos?

\section{OUTROS MARCADORES MOLECULARES}

O utros candidatos a marcadores moleculares foram descritos. Entre estes, telomerase, H M GI (Y), H BME1, FN-1, CITED-1, TPO, CK 19, GAL-3, RASSF1, RAS, PTEN e CAV1 (35-45). Até o momento, nenhum destes marcadores se mostrou eficiente em distinguir as lesões benignas das malignas e, portanto, não têm sido aplicados na prática clínica.

Sendo a carcinogênese um processo complexo e associado a múltiplas alterações genéticas, a identificação de um único marcador capaz de classificar todas as lesões com alta sensibilidade e especificidade é um grande desafio ou, talvez, inexeqüível. Por exemplo, GAL-3 foi capaz de distinguir AFT de CFT com boa sensibilidade e especificidade $(37,46)$, mas quando testada em outras populações este dado não foi confirmado $(47,48)$. Esta discrepância na literatura também ocorre para os demais marcadores. Assim, sugere-se que a associação entre os marcadores possa aumentar a sensibilidade e a especificidade.
Prasad e cols. testaram um painel de marcadores contendo GAL 3, FN 1, CITED 1, H BME1 e CK19. Os autores sugerem que a combinação da expressão de dois dos marcadores GAL3, HBME 1 e FN 1 foi observada somente em carcinomas e, portanto, é capaz de diferenciar AFT de todos os carcinomas derivados das células foliculares com sensibilidade de $82 \%$ (GAL 3 e FN 1) e $62 \%$ (H BME1 e FN 1). Vale a pena comentar que somente 6 casos de CFT foram investigados, sendo a grande maioria casos de CPT e VFCPT. D os 6 casos de CFT, somente 3 foram positivos para dois destes marcadores. Além disso, quando incluídas na análise outras lesões benignas como bócio e hiperplasia, que também são fonte de erro no diagnóstico, estes marcadores mostraram baixa especificidade. Por exemplo, $55 \%$ dos bócios expressam GAL 3, 31\% expressam CK19, 7\% expressam FN 1 e 3\% expressam H BM E1. Ainda, a co-expressão de dois destes marcadores, declarada como específica de carcinomas, foi observada em $38 \%$ dos bócios.

O utro painel de anticorpos, que consiste em GAL3, TPO, CK19, KS e HBME1, foi testado em material obtido da PAAF e comparado com material conservado em parafina dos mesmos pacientes (49). Os autores propõem um protocolo para avaliação dos nódulos diagnosticados como PF, sendo a análise inicial a imunoistoquímica empregando o anticorpo para GAL3. Segundo o protocolo, todos os nódulos positivos devem ser encaminhados para cirurgia sem adicional avaliação imunoistoquímica. Os nódulos negativos para GAL3 devem ser investigados quanto à expressão de CK19 e HBME1. Em presença de um resultado negativo do segundo marcador, é sugerido que o médico acompanhe o paciente clinicamente, incluindo uma nova PAAF nos próximos 6-12 meses e reavaliação por imunoistoquímica. Eles acreditam que em caso de falso-negativo, 0 tratamento seria adiado por no máximo 12 meses. Em resultado positivo do segundo marcador, este deve ser encaminhado para cirurgia. Segundo os autores, GAL3 e H BM E1 diferenciam as lesões foliculares convencionais (FTA e CFT), enquanto GAL3 e CK19 distinguem $\mathrm{ACH}$ de $\mathrm{CCH}$ com alta sensibilidade e especificidade. O s autores sugerem que a discrepância observada nos vários trabalhos provavelmente é decorrente da metodologia utilizada na imunoistoquímica (49).

Interessantemente, outros grupos têm associado a expressão de GAL 3 principalmente a CPT , bócios e outras lesões benignas, mas raramente ao CFT. A expressão de HBMEl é positiva em casos de $\mathrm{ACH}$ (12\%) e AFT (55\%) $(41,48,50-53)$.

Portanto, o protocolo de screning inicial com GAL 3 (49) dever ser analisado com muita cautela, não só pelos casos falso-negativos de CFT, mas pelo grande 
número falso-positivos. Mesmo que a positividade de GAL3 ou ainda HBME1 tenha sido focal nas lesões benignas, como al guns autores discutem, como será esta interpretação no material obtido da PAAF? Embora os autores acreditem que um atraso de 12 meses no tratamento não implique em conseqüências mais sérias para os pacientes, nos casos de CFT negativo para GAL 3 que permanecem negativos e cujo tamanho do nódulo não varie muito, como será o tratamento? D oze meses de atraso no tratamento realmente não faz diferença?

Alterações associadas especificamente ao CPT, como a mutação no gene BRAF ou ainda rearranjos do tipo RET/ PTC, também têm sido propostas para serem utilizadas no material obtido da PAAF numa tentativa de classificar os nódulos em benignos e malignos. Entretanto, a mutação V600E encontrada no exon 15 do gene BRAF ocorre exclusivamente na forma clássica de CPT (30-69\%), dependendo da casuística estudada (54-56). Portanto, além de não ser identificado em todos os casos de CPT da forma clássica, não identifica as lesões mais comumente agrupadas como lesões foliculares que são as VFCPT. Se este marcador pode ser utilizado ou não como marcador de prognóstico, isso não será discutido nesta revisão.

\section{DIAGNÓSTICO DE NÓDULOS COM PADRÃO FOUCULAR: NOVAS FERAMENTAS}

Tendo em vista o fato de que o desenvolvimento e a progressão dos tumores são decorrentes do acúmulo de alterações genéticas e/ ou epigenéticas no genoma das células somáticas tumorais e que essas alterações resultam em modulação da expressão gênica, a caracterização do perfil de expressão gênica dos tumores tem se tornado uma ferramenta importante para a descoberta de genes que estejam envolvidos na patogênese dos tumores e que possam ser utilizados com marcadores de diagnóstico, prognóstico ou ainda alvos terapêuticos.

Metodologias que utilizam sistemas fechados onde os genes são dispostos em arranjos gênicos como CD N A microarray e oligonucleotídeo array têm sido utilizadas para caracterizar a "assinatura molecular" e identificar genes diferencialmente expressos em cada uma das lesões comumente agrupadas como PF. Estas análises têm contribuído para aumentar a compreensão das diferenças moleculares existentes entre os diferentes subtipos de tumores foliculares e estão resumidas na tabela 1.

Nosso grupo utilizou macroarray com o objetivo de identificar novos marcadores. Entre os genes identificados, 5 foram selecionados para validação em diferentes subtipos de tumores da tiróide. A validação dos achados mostrou que os marcadores eram diferencialmente expressos nos diferentes subtipos tumorais e podem contribuir para a compreensão da patogênese dos tumores da tiróide, não eram eficientes para serem utilizados como marcadores de diagnóstico (57).

Barden e cols. investigaram o perfil de expressão gênica de AFT eCFT e identificaram 105 genes diferencialmente expressos. $0 \mathrm{~s}$ autores sugerem a análise destes 105 genes candidatos em material obtido da PAAF (58).

Mazzanti e cols., empregando microarray, identificaram um grupo de 11 genes diferencialmente expressos entre as lesões benignas e malignas da tiróide (tabela 1). Dois modelos foram criados a partir da combinação da expressão destes 11 genes. 0 primeiro modelo é baseado na combinação de 10/ 11 genes e 0 segundo de 6/11 genes. Estes dois modelos foram utilizados para testar 10 amostras com diagnóstico desconhecido. Os resultados demonstraram que a combinação de 6 genes classificou corretamente 10/ 10 amostras (59). Posteriormente, o grupo investigou a expressão dos 6 genes selecionados por microarray através da metodologia de PCR em tempo real. Entretanto, três dos genes tiveram níveis semelhantes nas amostras benignas e malignas. Os autores discutem que mesmo com uma diferença pequena, estes genes são fundamentais para a correta classificação das amostras e devem ser incluídos na investigação. Somente com análises realizadas em outros laboratórios utilizando este painel de genes será possível dizer se este achado é reproduzível. Vale a pena salientar que, embora os autores discutiram que foram utilizadas amostras de subtipos comumente classificados como lesões foliculares, nestas duas análises não foram incluídos casos de CFT e ACH (60).

U m novo modelo de classificação, baseado nos níveis de expressão de três genes, permitiu que os autores discriminassem AFT de CFT. O s genes PCSK 2 e CCDN 2 apresentaram aumento de expressão em $A F T$, enquanto que PLA B tem aumento de expressão em CFT (61). Vale a pena comentar que 0 gene PCSK 2, diferentemente do descrito como um dos marcadores expressos em AFT por Weber e cols. em 2005, havia sido identificado no nosso screening inicial como marcador de CFT. Entretanto, a validação demonstrou que PCSK 2 não foi capaz de diferenciar AFT de CFT, pois estava expresso em $30-40 \%$ dos casos de AFT e em $30-69 \%$ dos CFT (62).

U ma crítica comum às análises que utilizam array é a falta de concordância entre os diferentes estudos e as exaustivas listas de genes geradas. Como selecionar entre a lista de genes aqueles que têm potencial para serem usados como marcadores biológicos ou 
Tabela 1. Resumo dos principais estudos que utilizaram array para identificar marcadores biológicos com aplicação no diagnóstico dos nódulos classificados como padrão folicular.

\begin{tabular}{|c|c|c|c|c|c|}
\hline AUTORES & $\begin{array}{l}\text { METODOLOGIA } \\
\text { UTILIZADA }\end{array}$ & $\begin{array}{l}\text { SCREENING } \\
\text { INICIAL } \\
\text { SUBTIPO }(=\mathbf{n})^{a}\end{array}$ & $\begin{array}{l}\text { MARCADORES } \\
\text { IDENTIFICADOS }\end{array}$ & VALIDAÇÃO b & CONCLUSÃO \\
\hline Arnaldo e cols. (57) & $\begin{array}{c}\text { Macroarray } \\
\text { (1.807 transcritos) }\end{array}$ & $\begin{array}{c}\text { ARO } \\
\text { NPA } \\
\text { WRO } \\
\text { Tiróide normal }\end{array}$ & $\begin{array}{l}505 \text { genes } \\
\text { diferencialmente } \\
\text { expressos entre as } \\
\text { linhagens celulares } \\
\text { e tiróide normal }\end{array}$ & $\begin{array}{c}\text { DCN, NPM1, DIO1, } \\
\text { DIO2 e CH8 }\end{array}$ & $\begin{array}{l}\text { Os marcadores mostraram-se } \\
\text { diferencialmente expressos entre } \\
\text { os diferentes subtipos tumorais } \\
\text { mas não foram capazes de } \\
\text { distinguir AFT e CFT }\end{array}$ \\
\hline Barden e cols. (58 & $\begin{array}{l}\text { Oligonucleotídeo } \\
\text { array } \\
(>12.000)\end{array}$ & $\begin{array}{l}\text { AFT (12) } \\
\text { CFT (7) }\end{array}$ & 105 genes & $\begin{array}{l}\text { ADM, ENPP2, } \\
\text { EMMPRIN, MET, } \\
\text { TGF } \beta \text { R2 }\end{array}$ & $\begin{array}{l}\text { Sugere o uso destes } 105 \\
\text { marcadores em material obtido da } \\
\text { PAAF }\end{array}$ \\
\hline Mazzanti e cols. (59) & $\begin{array}{c}\text { Microarray } \\
\text { (10.000 transcritos) }\end{array}$ & $\begin{array}{l}\text { NH (15) } \\
\text { AFT (16) } \\
\text { CPT (17) } \\
\text { VFCPT (15) }\end{array}$ & $\begin{array}{l}\text { C21orf4, KIT, LSM7, } \\
\text { SYNGR2, Hs.24183, } \\
\text { Hs.296031, FAM 13A1, } \\
\text { C11orf8, KIAA1128, } \\
\text { IMPACT e CDH1 }\end{array}$ & & $\begin{array}{l}\text { Gerou um modelo que utiliza a } \\
\text { combinação de } 6 \text { genes para } \\
\text { distinguir lesões benignas } \\
\text { (NH e AFT) das } \\
\text { malignas (CPT e VFCPT) }\end{array}$ \\
\hline Rosen e cols. (60) & & $\begin{array}{c}\text { NH (11) } \\
\text { AFT (15) } \\
\text { CPT (9) } \\
\text { VFCPT (12) }\end{array}$ & $\begin{array}{l}\text { Utilização do modelo } \\
\text { de Mazzanti e cols. }\end{array}$ & $\begin{array}{c}\text { C21orf4, KIT, LSM7, } \\
\text { SYNGR2, Hs.24183, } \\
\text { Hs.296031 }\end{array}$ & $\begin{array}{c}\text { Diferencia CPT e VFCPT de AFT } \\
\text { e NH das demais lesões com } \\
\text { sensibilidade de } 75 \% \\
\text { e especificidade de } 100 \%\end{array}$ \\
\hline Finley e cols. (74) & Microarray & $\begin{array}{c}\text { NH e AFT (14) } \\
\text { CPT e VFCPT (21) }\end{array}$ & 262 genes & $\begin{array}{l}\text { AM, TROP-2, MET, } \\
\text { NRP2, Trefoil }\end{array}$ & $\begin{array}{c}\text { Diferencia CPT das demais lesões } \\
\text { benignas com sensibilidade e } \\
\text { especificidade de }>90 \%\end{array}$ \\
\hline Weber e cols. (61) & $\begin{array}{c}\text { Microarray } \\
\text { (22.283 transcritos) }\end{array}$ & $\begin{array}{l}\text { AFT (12) } \\
\text { CFT (12) }\end{array}$ & $\begin{array}{c}\text { CCDN2, PLAB e } \\
\text { PCSK2 }\end{array}$ & $\begin{array}{c}\text { CCDN2, PLAB e } \\
\text { PCSK2 }\end{array}$ & $\begin{array}{l}\text { Diferencia AFT e CFT com } \\
\text { sensibilidade de } 100 \% \\
\text { e especificidade de } 96,7 \%\end{array}$ \\
\hline Chevillard e cols. & $\begin{array}{c}\text { Microarray } \\
\text { (5.760 transcritos) }\end{array}$ & $\begin{array}{l}\text { FTA (4) } \\
\text { CFT (3) } \\
\text { VFCPT (3) } \\
\text { CPT (2) }\end{array}$ & $\begin{array}{c}43 \text { genes } \\
\text { diferencialmente } \\
\text { expressos entre } \\
\text { AFT e CFT } \\
23 \text { genes entre } \\
\text { AFT e CPT } \\
52 \text { genes entre } \\
\text { CFT e CPT }\end{array}$ & $\begin{array}{c}\text { DUSP5, CYR61 e } \\
\text { SDC4 }\end{array}$ & $\begin{array}{l}\text { Identificou um grupo de genes } \\
\text { diferencialmente expressos em } \\
\text { AFT e CFT e entre estas lesões } \\
\text { e CPT }\end{array}$ \\
\hline Griffith e cols. (63) & Meta-análise & & $\begin{array}{l}\text { MET, TFF3, SERPINA1, } \\
\text { EPS8, TIMP1, TGFA, } \\
\text { QPCT, PROSP1, } \\
\text { CRABP1, FN1, FCGBP } \\
\text { e TPO }\end{array}$ & $\begin{array}{l}\text { Dez destes genes } \\
\text { foram validados em } \\
\text { diferentes estudos }\end{array}$ & $\begin{array}{c}\text { Estes marcadores são candidatos } \\
\text { a distinguir lesões benignas } \\
\text { de malignas }\end{array}$ \\
\hline
\end{tabular}

a NH (nódulo hiperplásico); AFT (adenoma folicular da tiróide); CPT (carcinoma papilífero da tiróide); VFCPT (variante folicular de carcinoma papilífero da tiróide); CFT (carcinoma folicular da tiróide).

b Validação por RT-PCR (síntese de cDNA usando a enzima transcripitase reversa seguida de reação em cadeia da polimerase) ou imunoistoquímica (IHC).

que têm importância na patogênese dos tumores da tiróide, daqueles genes cuja expressão é ilegítima? Com o objetivo de identificar genes cuja diferença de expressão era constante nos diferentes estudos, G riffith e cols. re-avaliaram as listas resultantes de 21 estudos publicados (63). N este trabalho foram incluídos dois trabalhos publicados pelo nosso grupo e que utilizaram metodologias "hightroughput” $(57,62)$.
U sando critérios de seleção bem definidos, eles identificaram 107 genes diferencialmente expressos e citados mais de uma vez, 18 foram reportados pelo menos duas vezes e doze citados pelo menos quatro vezes. O s autores descrevem uma lista de 12 genes, 10 dos quais foram validados por metodologias que investigam mRN A e/ ou proteína (PCR em tempo real e/ ou imunoistoquímica e elisa) (tabela 1). Os autores 
sugerem que estes genes candidatos poderão auxiliar no desenvolvimento de um painel de marcadores que terá suficiente sensibilidade e especificidade para diagnóstico dos tumores da tiróide. U ma análise utilizando estes marcadores em material obtido da PAAF é necessária para rejeitar ou aceitar tal hipótese. Entretanto, devido à quantidade de material obtido da PAAF e 0 custo do teste, o uso de 12 marcadores não é desejável. 0 utro fator que deve ser levado em consideração é que entre esses 12 marcadores, são listados genes cuja eficiência em distinguir lesões benignas das malignas é questionável como, por exemplo, TPO .

Ainda com relação ao perfil de expressão gênica, alguns autores têm investigado o perfil de expressão em uma nova classe de pequenos RNAs, também denominados microRnAs ou miRNAs, com 0 objetivo de identificar marcadores de diagnóstico e prognóstico. Esta classe de pequenos RNAs, que apesar de serem transcritos não codificam proteínas, exerce suas funções através da regulação da transcrição gênica (64). Recentemente, um grupo identificou um aumento de expressão dos microRNAs miR-197 e miR-346 em CFT. Os autores sugerem que esses microRN As podem participar da progressão de AFT para CFT. Além disso, sugerem que estes ou ainda seus genes alvos possam ser candidatos a marcadores moleculares e alvos terapêuticos (65).

Além das ferramentas acima discutidas e que investigam o conjunto de RNA mensageiro que são expressas em um determinado tecido e que caracterizam o "transcriptoma", a análise do "proteoma" oferece uma vantagem que é a detecção dos reais realizadores das funções moleculares, que são as proteínas. U m estudo piloto investigou o perfil de expressão das proteínas em biópsias de CPT comparado com o de tiróide normal. 0 estudo revelou alguns candidatos a marcadores moleculares de malignidade (66).

\section{“BENCH-TO-BEDSIDE”, QUAIS SÃO AS PERSPECTIVAS?}

$\mathrm{Na}$ ausência de um biomarcador que eficientemente pudesse resolver esse problema clínico que é diferenciar as lesões benignas das malignas, investigamos 0 perfil de expressão gênica de uma lesão benigna (AFT) e de uma lesão maligna (CFT). De posse das duas "assinaturas moleculares" poderíamos, então, compará-las e selecionar os melhores candidatos a marcadores de diagnóstico. Para essa investigação, optamos pela metodologia de SAGE. Esta metodologia foi escolhida porque, diversamente dos microarraysque se caracterizam por serem sistemas fechados, os quais investigam os genes presentes em uma determinada plataforma, SAGE nos permitiria identificar e quantificar "todos os genes" expressos em uma determinada amostra. Para maiores detalhes da metodologia, consultar as referências $(67,68)$.

A análise realizada usando SAGE e subseqüente validação dos genes candidatos por PCR em tempo real permitiu identificar quatro novos marcadores, DDIT3, ARG2, ITM 1 e C 1orf24. A combinação da expressão destes marcadores permitiu diagnosticar corretamente 19 das 23 amostras analisadas (83\%) (62).

Posterior validação por imunoistoquímica, usando anticorpos comerciais para DDIT 3 e ARG2, revelou que esses marcadores foram capazes de diferenciar AFT de CFT com alta especificidade $(90,6 \%)$ e sensibilidade $(85,2 \%)(62)$. Será que a associação com outros marcadores (ITM 1 e C1orf24) poderia aumentar a sensibilidade e a especificidade? Anticorpos para ITM 1 e Clorf24 (Niban) foram produzidos pelo nosso grupo e testados nas amostras de AFT e CFT previamente analisadas para DDIT3 e ARG2. Obtivemos uma sensibilidade de $100 \%$ para ITM 1 e C 1orf24 e especificidade de 89\% (C 1orf24) (tabela 2, figura 2) (69).

Vale a pena comentar que os falso-positivos eram 2 casos de adenomas de células de $\mathrm{H}$ ürthle e 1 adenoma atípico. A positividade era focal e, interessantemente, os 3 casos foram positivos para os 4 marcadores. D esta forma, a combinação dos 4 marcadores não aumentou a especificidade.

Com relação aos adenomas atípicos, alguns autores sugerem que alguns casos possam ser lesões intermediárias entre adenoma folicular e carcinoma indiferenciado, uma vez que mutações no gene supressor de tumor P53 foram identificadas em dois casos de adenoma atípico (70). O utros acreditam que os adenomas atípicos possam ser precursores de CFT ou CPT, pois apresentam características morfológicas e genéticas comuns a esses dois subtipos de carcinomas $(71,72)$.

Como discutido na primeira seção deste manuscrito, o termo padrão folicular não se restringe só a AFT e CFT, mas pode incluir outras lesões.

Todos os marcadores mostraram alta sensibilidade e especificidade quando testados nas demais lesões benignas e malignas comumente agrupas como padrão folicular (tabela 2, figura 2). I soladamente, ITM 1 teve maior especificidade e sensibilidade. Os falso-positivos foram 3 casos de nódulos hiperplásicos com células de $H$ ürthle. Esses 3 casos também foram positivos para os demais marcadores (69). Embora os dados sugiram que ITM 1 pode distinguir as lesões 
Tabela 2. Sensibilidade e especificidade para cada marcador.

\begin{tabular}{|c|c|c|c|c|}
\hline \multirow[t]{2}{*}{ Nome Marcador } & $\begin{array}{l}\text { Sensibilidade } \\
(95 \% \mathrm{CI})\end{array}$ & $\begin{array}{l}\text { Especificidade } \\
(95 \% \mathrm{Cl})\end{array}$ & $\begin{array}{l}\text { Sensibilidade } \\
(95 \% \mathrm{CI})\end{array}$ & $\begin{array}{l}\text { Especificidade } \\
(95 \% \mathrm{CI})\end{array}$ \\
\hline & \multicolumn{2}{|c|}{ CFT vs. AFT } & \multicolumn{2}{|c|}{ Maligno vs. Benigno } \\
\hline DDIT3 & $.85[.68, .94]^{*}$ & $.90[.76, .97]^{*}$ & $.90[.80, .95]$ & $.90[.80, .95]$ \\
\hline ARG2 & $.85[.68, .94]^{*}$ & $.90[.76, .97]^{*}$ & $.91[.82, .96]$ & $.88[.78, .94]$ \\
\hline ITM 1 & $1.00[.87,1.00]$ & $.85[.68, .94]$ & $1.00[.95,1.00]$ & $.87[76, .93]$ \\
\hline Clorf24 & $1.00[.87,1.00]$ & $.89[.72, .96]$ & $.97[.90, .99]$ & $.90[.80, .95]$ \\
\hline
\end{tabular}

A sensibilidade e a especificidade foram calculadas conforme previamente descrito (69).

CFT, carcinoma folicular da tiróide; AFT, adenoma folicular da tiróide.

Benigno: Nódulos Hiperplásicos ( $n=33)$ e adenoma folicular da tiróide $(n=27)$

Maligno: carcinoma folicular da tiróide $(n=25)$, variante folicular de carcinoma papilífero da tiróide $(n=27)$ e carcinoma papilífero da tiróide $(n=15)$.

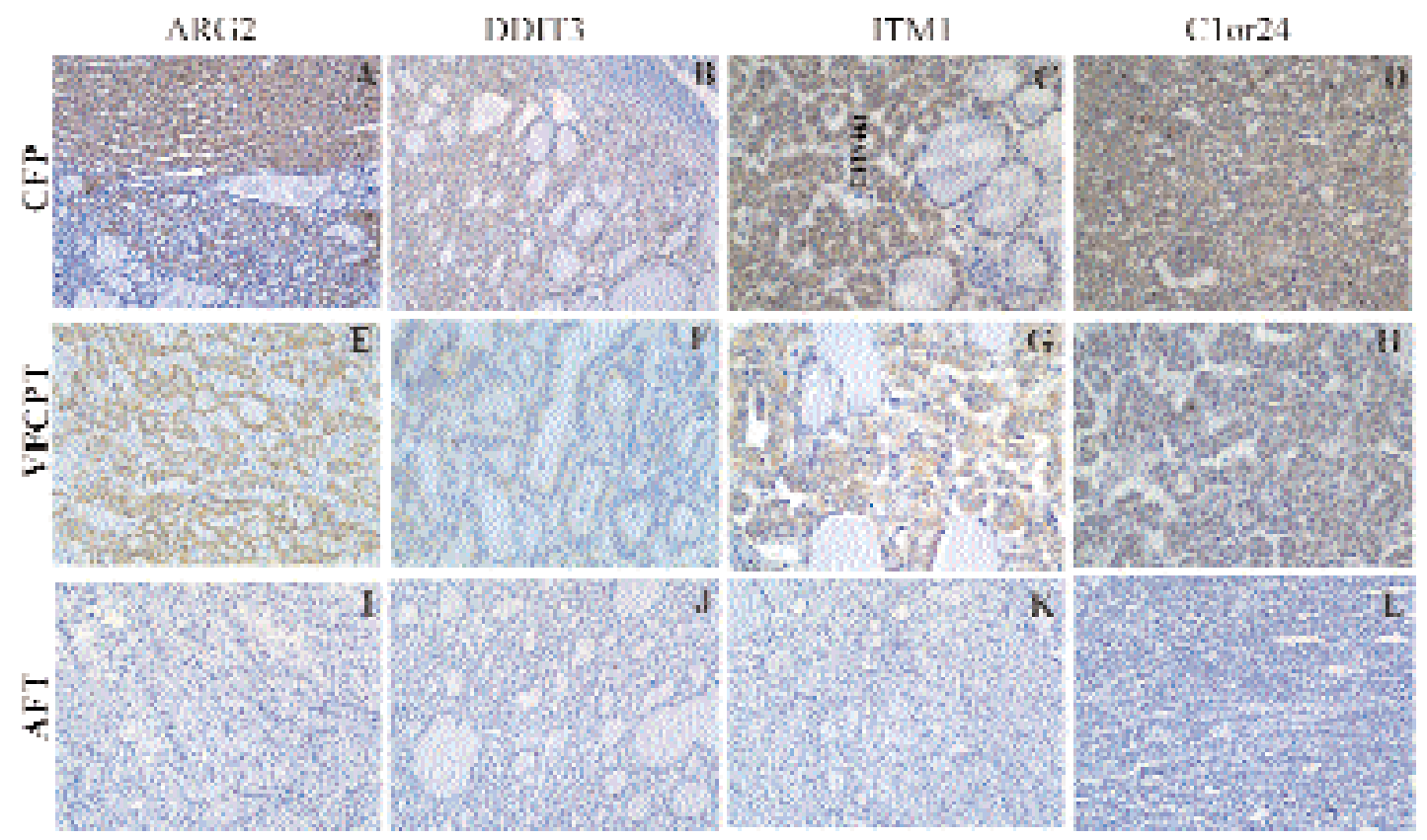

Figura 2. Imunoistoquímica empregando os anticorpos para ARG2, DDIT3, ITM1 e Clorf24 em secções de carcinoma folicular da tiróide (CFT), variante folicular de carcinoma papilífero (VFCPT) e adenoma folicular da tiróide (AFT). Os carcinomas (A-H) mostram forte reação positiva para todos os marcadores. Por outro lado, os adenomas (I-L) que são lesões benignas são negativos para todos os anticorpos. A ampliação original corresponde a 100X (A,B, I-L) e 400X (C-H).

benignas das malignas com alta sensibilidade e especificidade, a análise estatística demonstra que nenhum dos marcadores deve ser eliminado nas etapas posteriores do desenvolvimento de um teste pré-cirúrgico, uma vez que há sobreposição do intervalo de confiança (tabela 2).

U ma vez que desejávamos desenvolver um teste pré-cirúrgico barato e de fácil implementação na rotina laboratorial, estes marcadores foram testados em material obtido da PAAF de nódulos diagnosticados co- mo padrão folicular utilizando a metodologia de imunocitoquímica. Entre os seis nódulos analisados, cinco casos foram submetidos a tiroidectomia. A comparação com os dados obtidos da análise histológica revelou que $5 / 5$ casos foram corretamente classificados pelos marcadores (69).

Três meses após a nossa publicação validando os 4 marcadores nas várias lesões (69), um grupo japonês publicou um trabalho sugerindo que $\mathrm{N}$ iban (também denominado C 1orf24) era um "novo marcador" tu- 
moral em tiróide (73). Semelhante aos nossos achados, algumas lesões benignas com células de $\mathrm{H}$ ürthle foram focalmente positivas para a expressão de C 1orf24. 0 grupo sugere que talvez $\mathrm{N}$ iban seja um marcador de progressão tumoral.

Com relação à expressão destes marcadores nos estudos de array, DDIT3 e ARG2 estavam entre os genes listados como diferencialmente expressos em CFT mas não foram validados (Barden, 2003 \#7; Ying, 2003 \#202). C 1or24 e ITM 1 não foram identificados, muito provavelmente porque estes genes não estavam presentes nas plataformas usadas, deixando clara a vantagem de SAGE sobre as outras metodologias.

A té agora, as decisões de tratamento têm sido predominantemente baseadas na avaliação dos dados clínicos e citológicos do nódulo. Ao final das pesquisas, nossas e de outros grupos, esperamos ter marcadores tumorais que poderão ser investigados no material obtido de PAAF, que é um método minimamente invasivo, seguro e barato.

0 uso de marcadores moleculares, associado à análise citológica, é uma nova concepção no diagnóstico dos nódulos tiroidianos. Com um diagnóstico pré-cirúrgico mais preciso teremos um tratamento adequando e, conseqüentemente, mais efetivo para os pacientes com câncer de tiróide.

\section{AGRADECIMENTOS}

Aos alunos Flávia L atini, Gisele O ler, Liliane Arnaldi, Cléber Camacho, Cláudia Nakabashi, que contribuíram para a realização dos trabalhos aqui citados. Aos colegas e colaboradores Gregory Riggins, Rui M aciel, Rosana D elcelo, J ennifer Shoemaker e Vitor Andrade.

As pesquisas desenvolvidas pelo grupo e citadas aqui contaram com o apoio da Fundação de Amparo à Pesquisa do Estado de São Paulo (04/ 15288-0 e 05/60330-8) e NIH Grant CA113461. JMC é pesquisadora do CN Pq e FADA-U NIFESP.

\section{REERÊNCIAS}

1. Tan GH, Gharib H. Thyroid incidentalomas: management approaches to nonpalpable nodules discovered incidentally on thyroid imaging. Ann Intern Med 1997;126:226-31.

2. Topliss D. Thyroid incidentaloma: the ignorant in pursuit of the impalpable. Clin Endocrinol (Oxf) 2004;60:18-20.

3. Goellner J R, Gharib H, Grant CS, J ohnson DA. Fine needle aspiration cytology of the thyroid, 1980 to 1986. Acta Cytol 1987;31:587-90.

4. Caraway NP, Sneige N, Samaan NA. Diagnostic pitfalls in thyroid fine-needle aspiration: a review of 394 cases. Diagn Cytopathol 1993;9:345-50.
5. Castro MR, Gharib H. Thyroid fine-needle aspiration biopsy: progress, practice, and pitfalls. Endocr Pract 2003;9:128-36.

6. Baloch ZW, Fleisher S, LiVolsi VA, Gupta PK. Diagnosis of "follicular neoplasm": a gray zone in thyroid fine-needle aspiration cytology. Diagn Cytopathol 2002;26:41-4.

7. Suster S. Thyroid tumors with a follicular growth pattern: problems in differential diagnosis. Arch Pathol Lab Med 2006;130:984-8.

8. Lloyd RV, Erickson LA, Casey MB, Lam KY, Lohse CM, Asa SL, et al. Observer variation in the diagnosis of follicular variant of papillary thyroid carcinoma. Am J Surg Pathol 2004;28:1336-40.

9. Baloch ZW, Gupta PK, Yu GH, Sack MJ , LiVolsi VA. Follicular variant of papillary carcinoma. Cytologic and histologic correlation. Am J Clin Pathol 1999;111:216-22.

10. Rago T, Di Coscio G, Basolo F, Scutari M, Elisei R, Berti P, et al. Combined clinical, thyroid ultrasound and cytological features help to predict thyroid malignancy in follicular and Hürthle cell thyroid lesions: results from a series of 505 consecutive patients. Clin Endocrinol (Oxf) 2007;66:13-20.

11. Yang GC, Liebeskind D, Messina AV. Should cytopathologists stop reporting follicular neoplasms on fine-needle aspiration of the thyroid? Cancer 2003;99:69-74.

12. J ain M, Khan A, Patwardhan N, Reale F, Safran M. Follicular variant of papillary thyroid carcinoma: a comparative study of histopathologic features and cytology results in 141 patients. Endocr Pract 2001;7:79-84.

13. LiVolsi VA, Baloch ZW. Follicular neoplasms of the thyroid: view, biases, and experiences. Adv Anat Pathol 2004;11:279-87.

14. Smith J, Cheifetz RE, Schneidereit N, Berean K, Thomson T. Can cytology accurately predict benign follicular nodules? Am J Surg 2005;189:592-5.

15. Chow LS, Gharib H, Goellner J R, van Heerden J A. Nondiagnostic thyroid fine-needle aspiration cytology: management dilemmas. Thyroid 2001;11:1147-51.

16. Logani S, Gupta PK, LiVolsi VA, Mandel S, Baloch ZW. Thyroid nodules with FNA cytology suspicious for follicular variant of papillary thyroid carcinoma: follow-up and management. Diagn Cytopathol 2000;23:380-5.

17. Deveci MS, Deveci G, LiVolsi VA, Baloch ZW. Fine-needle aspiration of follicular lesions of the thyroid. Diagnosis and follow-Up. Cytojournal 2006;3:9.

18. Kroll TG, Sarraf P, Pecciarini L, Chen CJ , Mueller E, Spiegelman BM, et al. PAX8-PPAR $\gamma 1$ fusion oncogene in human thyroid carcinoma [corrected]. Science 2000;289:1357-60.

19. Nikiforova MN, Biddinger PW, Caudill CM, Kroll TG, Nikiforov YE. PAX8-PPAR $\gamma$ rearrangement in thyroid tumors: RT-PCR and immunohistochemical analyses. Am J Surg Pathol 2002;26:1016-23.

20. Nakabashi CC, Guimarães GS, Michaluart $P$, J $r$, Ward LS Cerutti J M, Maciel RM. The expression of PAX8-PPAR $\gamma$ rearrangements is not specific to follicular thyroid carcinoma. Clin Endocrinol (Oxf) 2004;61:280-2.

21. Herrmann MA, Hay ID, Bartelt DH, J r., Ritland SR, Dahl RJ , Grant CS, et al. Cytogenetic and molecular genetic studies of follicular and papillary thyroid cancers. J Clin Invest 1991;88:1596-604.

22. Marques AR, Espadinha $C$, Catarino AL, Moniz S, Pereira T, Sobrinho LG, et al. Expression of PAX8-PPAR $\gamma 1$ rearrangements in both follicular thyroid carcinomas and adenomas. J Clin Endocrinol Metab 2002;87:3947-52.

23. Cheung L, Messina M, Gill A, Clarkson A, Learoyd D, Delbridge $L$, et al. Detection of the PAX8-PPAR $\gamma$ fusion oncogene in both follicular thyroid carcinomas and adenomas. J Clin Endocrinol Metab 2003;88:354-7.

24. Reddi HV, Mclver B, Grebe SK, Eberhardt NL. The PAX8/PPAR $\gamma$ oncogene in thyroid tumorigeneseis. Endocrinology 2007;148(3):932-5.

25. French CA, Alexander EK, Cibas ES, Nose V, Laguette J, Faquin W, et al. Genetic and biological subgroups of lowstage follicular thyroid cancer. Am J Pathol 2003;162:105360. 
26. Castro P, Rebocho AP, Soares RJ , Magalhães J , Roque L, Trovisco $V$, et al. PAX8-PPAR $\gamma$ rearrangement is frequently detected in the follicular variant of papillary thyroid carcinoma. J Clin Endocrinol Metab 2006;91:213-20.

27. Castro $P$, Roque L, Magalhães J , Sobrinho-Simões M. A subset of the follicular variant of papillary thyroid carcinoma harbors the PAX8-PPAR $\gamma$ translocation. Int J Surg Pathol 2005; 13:235-8

28. Nikiforova MN, Lynch RA, Biddinger PW, Alexander EK, Dorn GW, 2nd, Tallini G, et al. RAS point mutations and PAX8PPAR rearrangement in thyroid tumors: evidence for distinct molecular pathways in thyroid follicular carcinoma. J Clin Endocrinol Metab 2003:88:2318-26.

29. Sahin M, Allard BL, Yates M, Powell J G, Wang XL, Hay ID, et al. PPAR $\gamma$ staining as a surrogate for PAX8/PPAR $\gamma$ fusion oncogene expression in follicular neoplasms: clinicopathological correlation and histopathological diagnostic value. J Clin Endocrinol Metab 2005;90:463-8.

30. Martelli ML, Iuliano R, Le Pera I, Sama I, Monaco C, Cammarota $\mathrm{S}$, et al. Inhibitory effects of peroxisome poliferatoractivated receptor gamma on thyroid carcinoma cell growth. J Clin Endocrinol Metab 2002;87:4728-35.

31. Gregory Powell J , Wang X, Allard BL, Sahin M, Wang XL, Hay ID, et al. The PAX8/PPAR $\gamma$ fusion oncoprotein transforms immortalized human thyrocytes through a mechanism probably involving wild-type PPAR $\gamma$ inhibition. Oncogene 2004:23:3634-41.

32. Au AY, McBride C, Wilhelm KG, J r., Koenig RJ, Speller B, Cheung $L$, et al. PAX8-peroxisome proliferator-activated receptor gamma (PPAR $\gamma$ ) disrupts normal PAX8 or PPAR transcriptional function and stimulates follicular thyroid cell growth. Endocrinology 2006;147:367-76.

33. Giordano TJ , Au AY, Kuick R, Thomas DG, Rhodes DR, Wilhelm KG, J r., et al. Delineation, functional validation, and bioinformatic evaluation of gene expression in thyroid follicular carcinomas with the PAX8-PPAR $\gamma$ translocation. Clin Cancer Res 2006:12:1983-93.

34. Lacroix L, Lazar V, Michiels S, Ripoche H, Dessen P, Talbot M, et al. Follicular thyroid tumors with the PAX8-PPAR $\gamma 1$ rearrangement display characteristic genetic alterations. Am J Pathol 2005:167:223-31.

35. Saji M, Xydas S, Westra WH, Liang CK, Clark DP, Udelsman $\mathrm{R}$, et al. Human telomerase reverse transcriptase (hTERT) gene expression in thyroid neoplasms. Clin Cancer Res 1999:5:1483-9.

36. Henry M, Zanelli E, Malthiery Y. Anti-human thyroid peroxidase and anti-human thyroglobulin antibodies present no cross-reactivity on recombinant peptides. Clin Exp Immunol 1991;86:478-82.

37. Xu XC, el-Naggar AK, Lotan R. Differential expression of galectin-1 and galectin-3 in thyroid tumors. Potential diagnostic implications. Am J Pathol 1995;147:815-22.

38. Schroder S, Wodzynski A, Padberg B. [Cytokeratin expression of benign and malignant epithelial thyroid gland tumors. An immunohistologic study of 154 neoplasms using 8 different monoclonal cytokeratin antibodies]. Pathologe 1996; $17: 425-32$.

39. Chiappetta G, Tallini G, De Biasio MC, Manfioletti G, Martinez-Tello FJ , Pentimalli F, et al. Detection of high mobility group I HMGI(Y) protein in the diagnosis of thyroid tumors: HMGI(Y) expression represents a potential diagnostic indicator of carcinoma. Cancer Res 1998;58:4193-8.

40. Sack MJ, Astengo-Osuna C, Lin BT, Battifora H, LiVolsi VA. HBME-1 immunostaining in thyroid fine-needle aspirations: a useful marker in the diagnosis of carcinoma. Mod Pathol 1997; 10:668-74.

41. Prasad ML, Pellegata NS, Huang Y, Nagaraja HN, de la Chapelle A, Kloos RT. Galectin-3, fibronectin-1, CITED-1, HBME1 and cytokeratin-19 immunohistochemistry is usefu for the differential diagnosis of thyroid tumors. Mod Pathol 2005; 18:48-57.

42. Lloyd RV. Distinguishing benign from malignant thyroid lesions: galectin 3 as the latest candidate. Endocr Pathol 2001;12:255-7.
43. Takano T, Matsuzuka F, Sumizaki H, Kuma K, Amino N. Rapid detection of specific messenger RNAs in thyroid carcinomas by reverse transcription-PCR with degenerate primers: specific expression of oncofetal fibronectin messenger RNA in papillary carcinoma. Cancer Res 1997;57:3792-7.

44. Aldred MA, Ginn-Pease ME, Morrison CD, Popkie AP, Gimm O, Hoang-Vu C, et al. Caveolin-1 and caveolin-2, together with three bone morphogenetic protein-related genes, may encode novel tumor suppressors down-regulated in sporadic follicular thyroid carcinogenesis. Cancer Res 2003;63:2864-71.

45. Halachmi N, Halachmi S, Evron E, Cairns P, Okami K, Saji M, et al. Somatic mutations of the PTEN tumor suppressor gene in sporadic follicular thyroid tumors. Genes Chromosomes Cancer 1998:23:239-43.

46. Orlandi F, Saggiorato E, Pivano G, Puligheddu B, Termine A, Cappia $S$, et al. Galectin-3 is a presurgical marker of human thyroid carcinoma. Cancer Res 1998:58:3015-20.

47. Cvejic D, Savin S, Paunovic I, Tatic S, Havelka M, Sinadinovic $\mathrm{J}$. Immunohistochemical localization of galectin-3 in malignant and benign human thyroid tissue. Anticancer Res 1998; $18: 2637-41$

48. Martins L, Matsuo SE, Ebina KN, Kulcsar MA, Friguglietti CU, Kimura ET. Galectin-3 messenger ribonucleic acid and protein are expressed in benign thyroid tumors. J Clin Endocrinol Metab 2002;87:4806-10.

49. Saggiorato E, De Pompa R, Volante M, Cappia S, Arecco F, Dei Tos AP, et al. Characterization of thyroid 'follicular neoplasms' in fine-needle aspiration cytological specimens using a panel of immunohistochemical markers: a proposal for clinical application. Endocr Relat Cancer 2005;12:305-17.

50. Cheung CC, Ezzat S, Freeman J L, Rosen IB, Asa SL. Immunohistochemical diagnosis of papillary thyroid carcinoma. Mod Pathol 2001;14:338-42.

51. Scognamiglio T, Hyjek E Kao I Chen YT Diagnostic usefulness of HBME1, galectin-3, CK19, and CITED1 and evaluation of their expression in encapsulated lesions with questionable features of papillary thyroid carcinoma. Am J Clin Pathol 2006:126:700-8

52. Volante M, Bozzalla-Cassione F, DePompa R, Saggiorato E, Bartolazzi A, Orlandi F, et al. Galectin-3 and HBME-1 expression in oncocytic cell tumors of the thyroid. Virchows Arch 2004:445:183-8.

53. de Matos PS, Ferreira AP, de Oliveira Facuri F, Assumpção LV, Metze K, Ward LS. Usefulness of HBME-1, cytokeratin 19 and galectin-3 immunostaining in the diagnosis of thyroid malignancy. Histopathology 2005;47:391-401.

54. Kimura ET, Nikiforova MN, Zhu Z, Knauf J A, Nikiforov YE, Fagin 」 A. High prevalence of BRAF mutations in thyroid cancer: genetic evidence for constitutive activation of the RET/PTC-RAS-BRAF signaling pathway in papillary thyroid carcinoma. Cancer Res 2003;63:1454-7.

55. Oler G, Ebina KN, Michaluart P, J r., Kimura ET, Cerutti J . Investigation of BRAF mutation in a series of papillary thyroid carcinoma and matched-lymph node metastasis reveals a new mutation in metastasis. Clin Endocrinol (Oxf) 2005:62:509-11.

56. Cohen Y, Xing M, Mambo E, Guo Z, Wu G, Trink B, et al. BRAF mutation in papillary thyroid carcinoma. J Natl Cancer Inst 2003:95:625-7.

57. Arnaldi LA, Borra RC, Maciel RM, Cerutti J M. Gene expression profiles reveal that DCN, DIO1, and $\mathrm{DIO} 2$ are underexpressed in benign and malignant thyroid tumors. Thyroid 2005:15:210-21.

58. Barden CB, Shister KW, Zhu B, Guiter G, Greenblatt DY, Zeiger MA, et al. Classification of follicular thyroid tumors by molecular signature: results of gene profiling. Clin Cancer Res 2003;9:1792-800.

59. Mazzanti C, Zeiger MA, Costouros NG, Umbricht C, Westra WH, Smith $\mathrm{D}$, et al. Using gene expression profiling to differentiate benign versus malignant thyroid tumors. Cancer Res 2004; 64:2898-903.

60. Rosen J , He M, Umbricht C, Alexander HR, Dackiw AP, Zeiger $M A$, et al. A six-gene model for differentiating benign from malignant thyroid tumors on the basis of gene expression. Surgery 2005;138:1050-6; discussion 1056-7. 
61. Weber F, Shen L, Aldred MA, Morrison CD, Frilling A, Saji M, et al. Genetic classification of benign and malignant thyroid follicular neoplasia based on a 3-gene combination. J Clin Endocrinol Metab 2005;90:2512-21.

62. Cerutti J M, Delcelo R, Amadei MJ, Nakabashi C, Maciel RM, Peterson B, et al. A preoperative diagnostic test that distinguishes benign from malignant thyroid carcinoma based on gene expression. J Clin Invest 2004;113:1234-42.

63. Griffith OL, Melck A, J ones SJ, Wiseman SM. Meta-analysis and meta-review of thyroid cancer gene expression profiling studies identifies important diagnostic biomarkers. J Clin Oncol 2006;24:5043-51.

64. Calin GA, Croce CM. MicroRNA-cancer connection: the beginning of a new tale. Cancer Res 2006;66:7390-4.

65. Weber F, Teresi RE, Broelsch CE, Frilling A, Eng C. A limited set of human MicroRNA is deregulated in follicular thyroid carcinoma. J Clin Endocrinol Metab 2006;91:3584-91.

66. Paron I, D'Ambrosio C, Scaloni A, Berlingieri MT, Pallante PL, Fusco A, et al. A differential proteomic approach to identify proteins associated with thyroid cell transformation. J Mol Endocrinol 2005;34:199-207.

67. Velculescu VE, Zhang L, Vogelstein B, Kinzler KW. Serial analysis of gene expression. Science 1995;270:484-7.

68. Cerutti J M, Riggins GJ , de Souza SJ . What can digital transcript profiling reveal about human cancers? Braz J Med Biol Res 2003;36:975-85.

69. Cerutti J M, Latini FR, Nakabashi C, Delcelo R, Andrade VP, Amadei MJ, et al. Diagnosis of suspicious thyroid nodules using four protein biomarkers. Clin Cancer Res 2006;12:3311-8.

70. Tzen CY, Huang YW, Fu YS. Is atypical follicular adenoma of the thyroid a preinvasive malignancy? Hum Pathol 2003;34:666-9.
71. Sarquis MS, Weber F, Shen L, Broelsch CE, J hiang SM, Zedenius $J$, et al. High frequency of loss of heterozygosity in imprinted, compared with nonimprinted, genomic regions in follicular thyroid carcinomas and atypical adenomas. J Clin Endocrinol Metab 2006;91:262-9.

72. Vasko VV, Gaudart J, Allasia C, Savchenko V, Di Cristofaro J , Saji M, et al. Thyroid follicular adenomas may display features of follicular carcinoma and follicular variant of papillary carcinoma. Eur J Endocrinol 2004; 151:779-86.

73. Matsumoto F, Fujii $\mathrm{H}$, Abe M, Kajino K, Kobayashi T, Matsumoto T, et al. A novel tumor marker, Niban, is expressed in subsets of thyroid tumors and Hashimoto's thyroiditis. Hum Pathol 2006;37:1592-600.

74. Finley DJ , Arora N, Zhu B, Gallagher L, Fahey TJ , 3rd. Molecular profiling distinguishes papillary carcinoma from benign thyroid nodules. J Clin Endocrinol Metab 2004;89:3214-23.

Endereço para comespondência:

J anete Cenutti

Universidade Federal de São Paulo

Rua Pedro de Toledo 781, 120 andar

04039-032 São Paulo, SP

Fax: (11) 5084-5231

E-mail: cenutti-endo@pesquisa.epm.br 